\title{
Risk Analysis of Shanghai Inter-Bank Offered Rate - A GARCH-VaR Approach
}

\author{
Maoguo Wu \\ Zeyang Li
}

SHU-UTS SILC Business School, Shanghai University, China

doi: 10.19044/esj.2017.v13n22p252 URL:http://dx.doi.org/10.19044/esj.2017.v13n22p252

\begin{abstract}
The inter-bank offered rate widely used by Chinese commercial banks is Shanghai Inter-Bank Offered Rate (Shibor). Shibor has experienced significant development since it was created. It offers different products by duration. Despite its importance in China's financial market, Shibor's risk has largely remained unexplored. Making contribution to existing literature on risk management of Shibor, this paper investigates risk of Shanghai InterBank Offered Rate (Shibor) utilizing GARCH-VaR method. The VaR of each product is calculated and compared while GARCH model is designed for a simpler calculation. In order to have a clearer view of Chinese commercial banks, the data selected is Shibor data sample from 2006 to 2016, which is measured by GARCH-VaR model and verified effectiveness by chi-square test. Empirical results show strong evidence for the need of Chinese commercial banks to change the status quo so that the great fluctuation and abnormal situation can be avoided. Policy implication, involving the interest rate management and internal problem in commercial banks, is proposed for financial regulators.
\end{abstract}

Keywords: Interest Rate Risk, Shibor, GARCH-VaR

\section{Introduction}

In 1980s, with large scale of financial liberalization, western developed countries first came to realize the importance and necessity of interest rate liberalization, and lessened the supervision of interest rate gradually, which resulted in floating interest rate. Compared to the action taken by western developed countries, China, limited by its economic condition and political system then, had a late start in the process of interest rate liberalization. In the early 1990s, influenced by economic globalization, China started following western developed countries' practice and reducing supervision of interest rate. In the June of 1996, the central bank of China, People's Bank of 
China, canceled the method of pricing the inter-bank interest rate by pegging it to the loan interest rate and achieved inter-bank interest rate liberalization. Afterwards, under the instruction and regulation of People's Bank of China, inter-bank market has developed rapidly and become a critical channel of short-term funding for commercial banks. Meanwhile, the inter-bank interest rate liberalization and the increase in the inter-bank trade volume cause a larger risk in inter-bank interest rate. In 2008, the financial crisis occurred. In the recession, the uncertainty of inter-bank rate rises, which leads to an increase in related risks and warns financial institutions of paying more attention to risk management.

In 2015, People's Bank of China decreased the deposit rate and deposit reserve ratio. The decrease means that the 20 -year interest rate liberalization revolution process has almost accomplished. However, revolution of the interest rate liberalization has not been completed yet. It is regarded as just the beginning because risk management of inter-bank offered rate of China's commercial banks needs to be improved no matter in terms of system regulation or risk ratings. Quantification of interest rate risk helps financial institutions to have a clearer view of risk volume. As a result, it is critical to establish an appropriate risk measurement model and scientific control method for financial institutions.

Previous research on inter-bank offered rate of Chinese commercial banks almost exclusively focuses on Chinese Inter-Bank Offered Rate (Chibor). Chibor has not been updated since 2015. Meanwhile, Shibor is replacing Chibor. Shibor offers different products by duration. Research on risk of different products is scanty. Contributing to empirical literature on risk of Shibor, this paper analyzes risk of Shanghai Inter-Bank Offered Rate (Shibor) by calculating and comparing risks of different products of Shibor using GARCH-VaR method.

The remaining part of this paper is organized as follows. Section 2 reviews related literature. Section 3 introduces background. Section 4 is devoted to empirical analysis. Section 5 proposes policy implication. Section 6 concludes the paper.

\section{Related Literature}

In the early stage, commercial bank offered rate risk management uses interest rate sensitivity gap model and the duration model to measure interest rate risk. Sensitivity gap model aims to solve the mismatch between the duration of asset and liability. The sensitivity gap model is based on static time point without considering the time value of currency. In the situation of interest rate fluctuation, the model cannot measure interest rate risk. Morgan (1982) divides asset and liability with different durations into different groups and calculates sensitivity gap. Arvan and Brueckner (1990) extends 
the sensitivity gap model which can calculate the sensitivity gap of floating interest rate mortgage loan. Macaulay (1992) proposes duration gap model. Kaufman and Nielson (1995) combines convexity and duration gap analysis and amends the yield curve so that the bond price can reflect the change in the interest rate more sensitively. Cox and Ross (1999) proposes random duration model, which enhances the accuracy, especially the interest rate risk measurement of yield curve. Shi (2005) compares two different gap analysis and VaR analysis on Chinese market adopting international risk management method and finds that international risk management method does not fit China's condition. $\mathrm{Xu}$ (2007) investigates the process of choosing dynamic and static decision through two different gap analysis and $\mathrm{VaR}$ analysis and finds that duration analysis fits China's condition well. Gao (2008) combines time value of money and risk capability of banks with sensitivity gap model, and proposes a modified gap calculation method. Huang (2001) combines inter-bank offered rate with interest rate liberalization and proposes a periodical interest risk management method. Later, VaR model and econometric method, like ARCH models, become the most prevalent method to measure inter-bank offered rate risk. $\mathrm{Xu}$ and Huang (2008) uses VaR method and calculates the value of $\mathrm{VaR}$ through estimation of interest rate volatility with GARCH model. Li and Ma (2007) argues that the application of GARCH-VaR cannot have a reliable result due to lack of data of Chinese commercial banks. Fan (2009) argues that improper changes in the interest rate caused by emergencies can be combined with GARCH model to calculate VaR, including the risk value of commercial banks in emergencies. Liu (2012) includes emergency in the inter-bank offered rate risk measurement. It simulates the emergency to data fitting phase while VaR condition is to put emergency into something excessing the expected risk value. In addition, $\mathrm{Hu}$ and $\mathrm{Su}$ (2014) investigates different distribution of inter-bank offered rate time series and provides further solution to interest rate risk measurement with improved model.

In the end of the 21 st century, with the development of global economy and the appearance of financial derivatives, the risks faced by commercial banks and financial institutions are more and more complex, which asks higher request for the financial institutions to prevent risk. The concept of value at risk was invented by J.P. Morgan and regarded as a new tool for measuring financial risk. Next, Jorion (1996) illustrates the mathematic basis, calculation process and application of the VaR model. The method translates risk into data. It can be applied to the combination of single asset and portfolios. VaR can be used to measure aggregate risk of the financial institution and please the demand of overall risk management. Chew and Lilian (1996) also concludes three main calculation methods of VaR, which are historical simulation method, parametric method and Monte Carlo 
simulation method. The application of these calculation methods provides more choices for commercial banks to defend and prevent interest risks. Not only can VaR manage interest rate risk through the position in the balance sheet but also it can prevent interest risk through reasonable usage of financial derivatives. The 2008 financial crisis caused abnormal changes in the financial market. In order to take emergency into consideration, Berkowitz (2008) proposes conditional VaR, the loss excessing the expected possibility and average.

In the background of economic globalization and interest rate liberalization, a model to predict and manage interest rate risk is badly needed so that the risk faced by financial institutions can be minimized and economy can be developed positively. The application of GARCH-VaR model in the interest rate risk measurement helps assess interest rate volatility. Due to the fact that the distribution has characteristics of "high peak and fat tail" and bunching variance, GARCH model describes timevarying characteristics well. Previous research always utilizes one or two models to analyze and contrast the results in order to identify "high peak and fat tail" characteristic, such as Gabriel (2002), Wu and Xie (2002).

There are obvious differences in regime between China and western countries. Empirical results derived using data from western countries cannot be directly applied to China. Besides, every GARCH model differs and focuses on different aspects, resulting in a difficulty in choosing GARCH model. Analysis framework of ARCH model is an indispensable and effective tool through the establishment of GARCH model to improve the effectiveness of VaR.

\section{Background}

As the premise of pricing of financial assets and products, and the development of interest market and economy, the benchmark interest rate means a lot to the effective management of interest rate. The benchmark interest rate always has the market standard, stability and transitivity. Deposit and loan interest rate, return of the bond, repurchase rate, commercial paper rate and inter-bank interest rate are important compositions of Chinese interest rate market system.

The inter-bank interest rate refers to the short-term loan interest rate among banks. There are two rates, which are bid rate and ask rate. One bank's bid rate is another bank's ask rate. The difference between bid and ask rate is the bank's return. Shanghai Inter-bank Offered Rate (Shibor) is based on the credit amount provided by the bank. It is the loan interest rate among commercial banks. Eight products are priced in accordance to Shibor, from $\mathrm{T}+1$ to a year. They are calculated by interest rates from 18 commercial banks. The aggregation of calculation removes the highest and value and the 
lowest value, and is divided by 14 to get the average value. Shibor is issued at 9:30 am Beijing Time. Shibor reflects the value of market fund and the price level of supply and demand. It is the standard of the condition of the bank industry, which provides a reference to the action of monetary policy. The significance of Shibor is that it is a sign of fund abundance. When central bank raises the reserve ratio or the expected, Shibor always increases to a certain extent. However, the decrease of Shibor means insufficiency of bank's fund and loose environment, which may result from open market operation. This provides the investment industry with a simpler market funding analysis.

The distribution of inter-bank offered rate always has the characteristics of "high peak and fat tail". Meanwhile, the variance of the interest rate changes by time. Fluctuation range of the variance remains large in a certain time or small in another, which is called cluster characteristics of yield volatility. The cluster characteristics of yield volatility means that volatility changes over time, leading to a dynamic inter-bank offered rate because the market must pay for the risk. With regard to the non-classical phenomenon that volatility changes with time, only two order or higher time-varying models can have an accurate description of the relation between risk and interest rate. The Autoregressive Conditional Heteroscedastic Model $(\mathrm{ARCH})$ and Generalized Autoregressive Conditional Heteroscedastic Model (GARCH) have a better explanation of the time-varying volatility.

When the random error has heteroscedasticity, error will be born if ordinary least square method is used. However, the usage of ARCH model can improve its precision and accuracy. When volatility is large, the estimated confidence level is small, so it is reliable. However, ARCH model has certain shortages. Firstly, in order to maintain the stationarity of ARCH model and non-negativity of the conditional volatility, unknown parameter is asked to be non-negative. Secondly, volatility only depends on the absolute value of lagged value of volatility regardless the positivity or negativity of variance. Thirdly, conditional volatility is a linear function of ARCH model. In order to alleviate existing problems of $\mathrm{ARCH}$ model, this paper conducts GARCH regression. The advantage of GARCH model is that its lower order is equivalent to the forecast of high order $\mathrm{ARCH}$ model and it is relatively easier to identify the process and estimate the parameter. Due to the fact that the conditional volatility of GARCH model is the function of lag residual square and lag conditional volatility, GARCH model can effectively reduce computational complexity.

\section{Empirical Analysis}

The data are gathered from the official website of Shibor between October 12, 2006 and March 18, 2016. The data includes 9,436 observation, 
which can be grouped by duration, i.e., overnight mean value of five days, weekly mean value of every two weeks, biweekly mean value of five days, and monthly mean value of five days. Besides, 10-day average and 20-day average are added to the four-term data to augment measurement, resulting in a total observation number of 18,792 . This paper calculates the VaR of each product by GARCH/TARCH model.

Most statistics theories and parameter tests are based on normal distribution, which is the most common distribution method. In the calculation process of $\mathrm{VaR}$, the method used by is delta normal distribution. It is used to transform interest rate by logarithm, which can effectively reduce the computational complexity. The quantile used to calculate $\mathrm{VaR}$ is $\alpha=0.01, z=2.3263$, which is under $99 \%$ confidence interval. The reduction of allowed error range has a better result in the comparison between the mean value of Shibor and the result of $\mathrm{VaR}$ of different products. Descriptive statistics, trend, and distribution of four different products of Shibor can be found through Figure 1 to Figure 8.
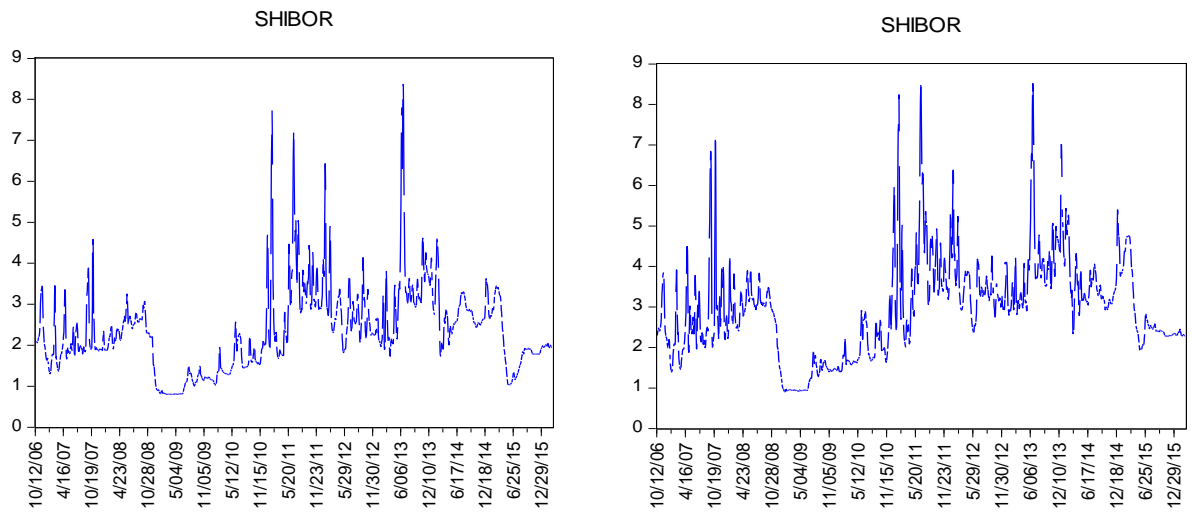

Figure 1

Figure 2

Overnight Mean Value of Five Days Weekly Mean Value of Five Days

SHIBOR

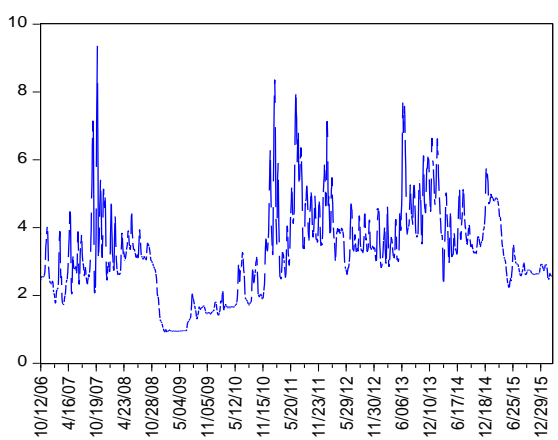

SHIBOR

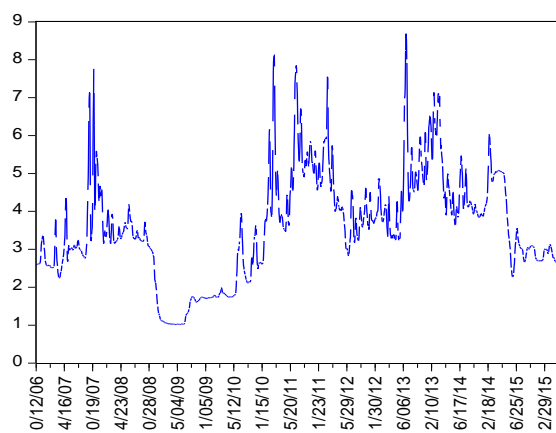

Figure 4

Figure 3

Biweekly Mean Value of Five Days

\section{Figure 4}

Monthly Mean Value of Five Days 
Four products of of Shibor all have a large fluctuation and irregular change without normal distribution. First peak of these four groups of data appeared in 2007. Then the mean sharply decreases and remains low. From 2010 to 2015, four different terms of Shibor all drastically fluctuated and tended to be stable in the end of 2015 .
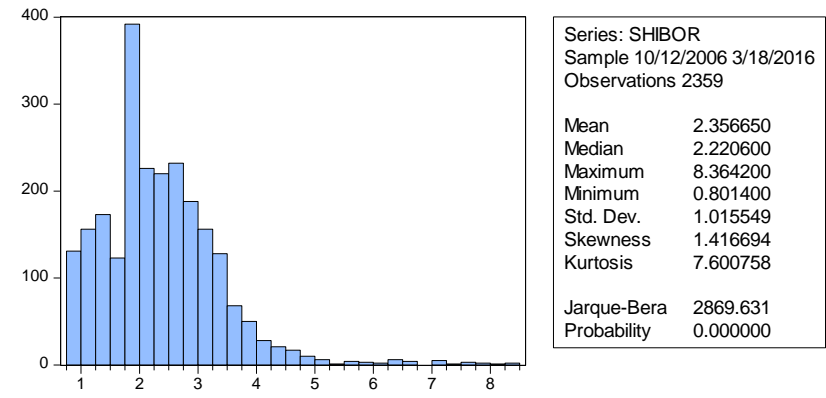

Figure 5 Overnight Mean Value of Five Days

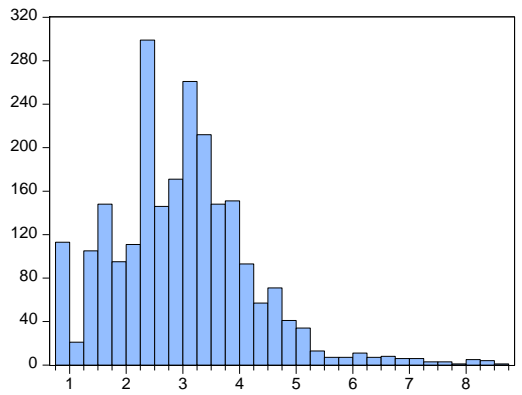

$$
\begin{array}{|ll}
\hline \multicolumn{2}{|l|}{\begin{array}{l}
\text { Series: SHIBOR } \\
\text { Sample 10/12/2006 3/18/2016 } \\
\text { Observations } 2359
\end{array}} \\
\text { Mean } & 2.984940 \\
\text { Median } & 2.962100 \\
\text { Maximum } & 8.515400 \\
\text { Minimum } & 0.904400 \\
\text { Std. Dev. } & 1.206080 \\
\text { Skewness } & 0.871208 \\
\text { Kurtosis } & 4.885940 \\
& \\
\text { Jarque-Bera } & 648.0159 \\
\text { Probability } & 0.000000
\end{array}
$$

Figure 6 Weekly Mean Value of Five Days

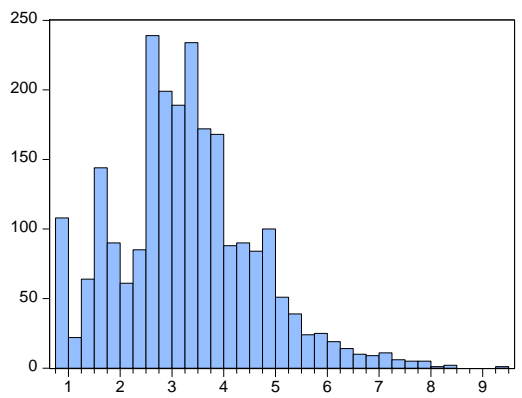

Series: SHIBOR

Sample 10/12/2006 3/18/2016 Observations 2359

Mean $\quad 3.291142$

Median $\quad 3.227200$

Maximum 9.356200

Minimum 0.925500

Std. Dev. $\quad 1.327972$

Skewness 0.57891

Kurtosis $\quad 3.676851$

Jarque-Bera $\quad 176.7958$

Probability $\quad 0.000000$

Figure 7 Biweekly Mean Value of Five Days 

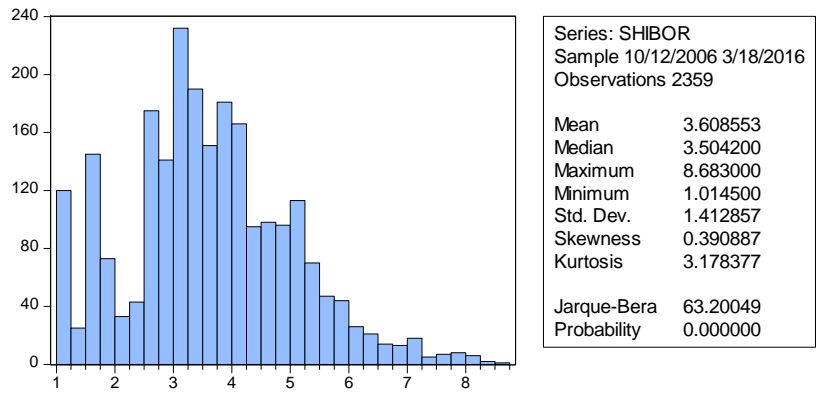

Figure 8 Monthly Mean Value of Five Days

It can also be seen that four different products of Shibor exhibit strong characteristics of high peak and fat tail. Agument Dickey-Fuller (ADF) test is conducted to test stationarity of each time series. The result is shown in Table 1.

Table 1 Descriptive Statistics and ADF Test

\begin{tabular}{llllll}
\hline Product & Mean & $\begin{array}{l}\text { Standard } \\
\text { Deviation }\end{array}$ & Skewness & Kurtosis & t \\
\hline $\begin{array}{l}\text { Overnight Mean } \\
\text { Value of Five Days }\end{array}$ & 2.35665 & 1.015549 & 1.416694 & 7.600758 & -4.222051 \\
\hline $\begin{array}{l}\text { Weekly Mean } \\
\text { Value of Five Days }\end{array}$ & 2.98494 & 1.20608 & 0.871208 & 4.88594 & -4.058809 \\
\hline $\begin{array}{l}\text { Biweekly Mean } \\
\text { Value of Five Days }\end{array}$ & 3.291142 & 1.327972 & 0.578912 & 3.676851 & -3.573087 \\
\hline $\begin{array}{l}\text { Monthly Mean } \\
\text { Value of Five Days }\end{array}$ & 3.608553 & 1.412857 & 0.390887 & 3.178377 & -3.12881 \\
\hline
\end{tabular}

Taking overnight mean value of five days as an example, the mean is 2.356650, standard deviation is 0.01718 , skewness is 0.199660 , and kurtosis is 5.457681. The kurtosis is higher than 3, showing that Shibor has the characteristics of high peak and fat tail. The other four groups of the data also have the same characteristic. In the stationarity test, the t-test is between -5 and -3 . In addition, the probability of corresponding $\mathrm{P}$ value is zero, indicating no unit root. Therefore, each time series is stationary. Every group of data is applied to a random walk model and processed residual autocorrelation. Afterwards ARCH effect is diagnosed before GARCH model is used. Serial correlation test result is displayed in Table 2.

Table 2 Serial Correlation Test

\begin{tabular}{lllll}
\hline Product & $\mathbf{F}$ & $\mathbf{p}$ & $\mathbf{T}$ \\
\hline $\begin{array}{l}\text { Overnight Mean Value of Five } \\
\text { Days }\end{array}$ & 625.5579 & 0.0000 & 6.031657 \\
\hline $\begin{array}{l}\text { Weekly Mean Value of Five Days } \\
\text { Biweekly Mean Value of Five } \\
\text { Days }\end{array}$ & 840.7883 & 0.0000 & 5.707767 \\
\hline Monthly Mean Value of Five Days & 4765.987 & 0.0000 & 6.515147 \\
\hline
\end{tabular}


Taking overnight mean value of five days as an example, it can be seen that p- value is zero, which shows that the residual square sequences of the equation are auto correlated. ARCH effect exists. The other three groups of data are also the same, with p-values indicating a significant serial correlation between the residual square sequences. Lag of serial correlation are shown through Figure 9 to Figure 12.

\begin{tabular}{|c|c|c|c|c|c|c|}
\hline Autocorrelation & Partial Correlation & & $\mathrm{AC}$ & PAC & Q-Stat & Prob \\
\hline & & 1 & 0.989 & 0.989 & 2308.3 & 0.000 \\
\hline & & 2 & 0.960 & -0.757 & 4486.4 & 0.000 \\
\hline & 回 & 3 & 0.921 & 0.169 & 6491.1 & 0.000 \\
\hline & 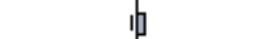 & 4 & 0.876 & 0.055 & 8307.2 & 0.000 \\
\hline & 吅 & 5 & 0.832 & 0.184 & 9943.9 & 0.000 \\
\hline$\square$ & 口 & 6 & 0.793 & 0.217 & 11431. & 0.000 \\
\hline$\square$ & $\square_{1}$ & 7 & 0.758 & -0.363 & 12792 & 0.000 \\
\hline & 旧 & 8 & 0.728 & 0.075 & 14047. & 0.000 \\
\hline & 吅 & 9 & 0.701 & 0.136 & 15213. & 0.000 \\
\hline 吊 & 吅 & 10 & 0.679 & 0.104 & 16305. & 0.000 \\
\hline
\end{tabular}

Figure 9 Overnight Mean Value of Five Days

\begin{tabular}{|c|c|c|c|c|c|c|}
\hline Autocorrelation & Partial Correlation & & $\mathrm{AC}$ & PAC & Q-Stat & Prob \\
\hline & & 1 & 0.989 & 0.989 & 2309.6 & 0.000 \\
\hline & I & 2 & 0.960 & -0.782 & 4489.5 & 0.000 \\
\hline & 吅 & 3 & 0.921 & 0.191 & 6493.9 & 0.000 \\
\hline$\square$ & 吕 & 4 & 0.876 & 0.145 & 8308.2 & 0.000 \\
\hline$\square$ & ص & 5 & 0.831 & 0.145 & 9942.4 & 0.000 \\
\hline$\square$ & 吅 & 6 & 0.792 & 0.185 & 11425 . & 0.000 \\
\hline & $\square$ । & 7 & 0.757 & -0.326 & 12784. & 0.000 \\
\hline & 紧 & 8 & 0.728 & 0.079 & 14040. & 0.000 \\
\hline & 口 & $g$ & 0.704 & 0.221 & 15215. & 0.000 \\
\hline & 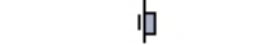 & 10 & 0.685 & 0.074 & 16327. & 0.000 \\
\hline \multicolumn{7}{|c|}{ Figure 10 Weekly Mean Value of Five Days } \\
\hline Autocorrelation & Partial Correlation & & $\mathrm{AC}$ & PAC & Q-Stat & Prob \\
\hline & & 1 & 0.990 & 0.990 & 2315.5 & 0.000 \\
\hline & & 2 & 0.965 & -0.764 & 4517.0 & 0.000 \\
\hline & 14 & 3 & 0.930 & 0.023 & 6559.8 & 0.000 \\
\hline & 吅 & 4 & 0.887 & 0.118 & 8422.1 & 0.000 \\
\hline & 响 & 5 & 0.844 & 0.235 & 10106. & 0.000 \\
\hline & 叫 & 6 & 0.804 & 0.305 & 11636. & 0.000 \\
\hline & $\square_{1}$ & 7 & 0.770 & -0.271 & 13039. & 0.000 \\
\hline$\square$ & 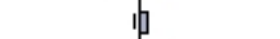 & 8 & 0.741 & 0.054 & 14341. & 0.000 \\
\hline$\square$ & 吅 & g & 0.721 & 0.148 & 15572 & 0.000 \\
\hline$\square$ & 吅 & 10 & 0.707 & 0.154 & 16757. & 0.000 \\
\hline
\end{tabular}

Figure 11 Biweekly Mean Value of Five Days 


\begin{tabular}{c|rrrrrr}
\hline \hline Autocorrelation & Partial Correlation & AC & PAC & Q-Stat & Prob \\
\hline \hline & & 1 & 0.996 & 0.996 & 2341.3 & 0.000 \\
& & & \\
\hline
\end{tabular}

Figure 12 Monthly Mean Value of Five Days

Figures above show that all four time series exhibit serial correlation, which means the residual square sequences have significant correlation. Cochrane-Orcutt AR(1) is augmented with each regression to eliminate serial correlation. ARCH-LM test on residual sequence is then conducted to identify whether residual sequence has ARCH effect or not. Only the one, which has ARCH effect and satisfies conditional heteroscedasticity, can be put into GARCH model. The result of four groups of ARCH-LM tests is listed in Table 3.

Table 3 ARCH Test

\begin{tabular}{ll}
\hline Product & F \\
\hline Overnight Mean Value of Five Days & 101703 \\
\hline Weekly Mean Value of Five Days & 105184.7 \\
\hline Biweekly Mean Value of Five Days & 119034.4 \\
\hline Monthly Mean Value of Five Days & 279665.1 \\
\hline
\end{tabular}

It is shown that $\mathrm{F}$ value is larger than the critical value and the probability is less than 0.1 . Hence, the null hypothesis is rejected and the residual sequences satisfy conditional heteroscedasticity.

After serial correlation test and $\mathrm{ARCH}$ test, four groups of residual sequences are found fit for GARCH model. GARCH model is established for four time series. The result is listed in Table 4.

The formula below is used to fit GARCH model.

$\sigma_{t}^{2}=\alpha_{0}+\sum_{i=1}^{p} \alpha_{i} r_{t-i}^{2}+\sum_{j=1}^{\alpha} \alpha_{j} \sigma_{t-j}^{2}$ 
Table 4 GARCH Regression Result

\begin{tabular}{llccccc}
\hline Product & \multicolumn{1}{c}{$\alpha_{0}$} & $\alpha_{1}$ & $\beta_{1}$ & $R^{2}$ & Log & Durbin \\
\hline $\begin{array}{l}\text { Overnight Mean } \\
\text { Value of Five Days }\end{array}$ & $\begin{array}{l}3.36 \mathrm{E}- \\
07\end{array}$ & 3.928713 & 0.192821 & 0.977223 & 4136.221 & 0.501037 \\
\hline $\begin{array}{l}\text { Weekly Mean Value } \\
\text { of Five Days }\end{array}$ & $\begin{array}{l}1.70 \mathrm{E}- \\
06\end{array}$ & 1.348714 & 0.345344 & 0.977981 & 3063.085 & 0.435925 \\
\hline $\begin{array}{l}\text { Biweekly Mean } \\
\text { Value of Five Days }\end{array}$ & $\begin{array}{l}1.39 \mathrm{E}- \\
06\end{array}$ & 1.350029 & 0.303269 & 0.980519 & 2952.386 & 0.465 \\
\hline $\begin{array}{l}\text { Monthly Mean Value } \\
\text { of Five Days }\end{array}$ & $\begin{array}{l}5.17 \mathrm{E}- \\
07\end{array}$ & 1.645356 & 0.230045 & 0.991632 & 4345.219 & 0.288595 \\
\hline
\end{tabular}

In the analysis of the fitting results of GARCH model, ARCH tests are conducted again to identify whether the correlation of data residual and ARCH effect exist.

\begin{tabular}{ll}
\multicolumn{2}{c}{ Table 5 GARCH Model F Value under ARCH Test } \\
\hline Product & F \\
\hline Overnight Mean Value of Five Days & $0.016012(0.8993)$ \\
\hline Weekly Mean Value of Five Days & $0.000924(0.9758)$ \\
\hline Biweekly Mean Value of Five Days & $0.000192(0.9889)$ \\
\hline Monthly Mean Value of Five Days & $0.200464(0.6544)$ \\
\hline
\end{tabular}

Table 5 shows the test result on residual sequence to confirm whether GARCH model can depict the characteristics of Shibor volatility. All mean values of five days show that goodness of fit and $\mathrm{P}$ value are larger, which indicates that residual sequence does not have heteroscedasticity. GARCH model can match the characteristics of heteroscedasticity well. VaR is calculated according to the formula.

$\mathrm{VaR}=\mathrm{W}_{0}(\mu-\alpha \sigma) \sqrt{\Delta \mathrm{t}}$.

In the 99\% confidence level, the corresponding critical quantile value is 2.3263. After forecasting $\mathrm{VaR}$, the movement of $\mathrm{VaR}$ is shown in the following figures.

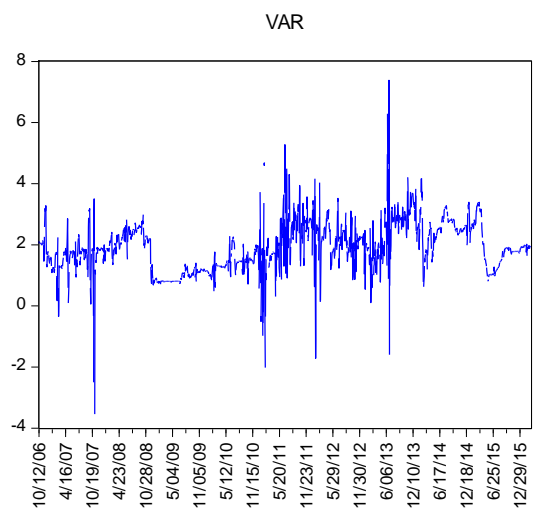

Figure 13 Overnight VaR

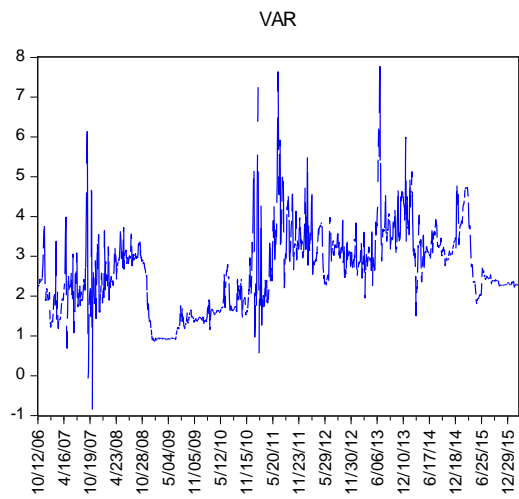

Figure 14 Weekly VaR 


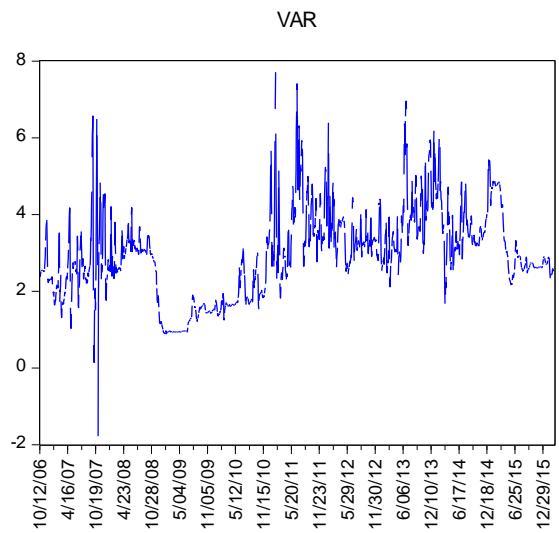

Figure 15 Biweekly VaR

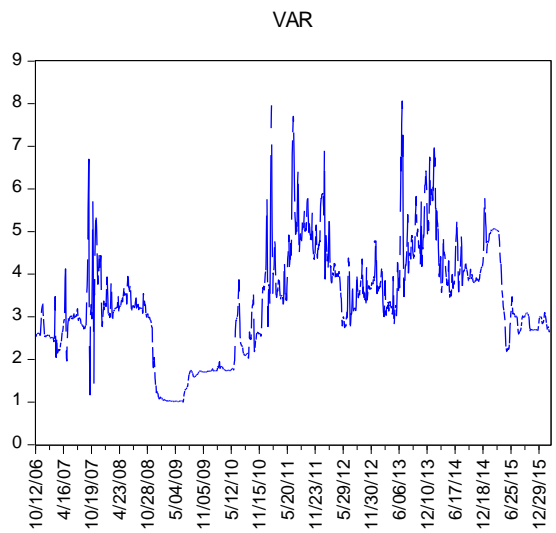

Figure 16 Monthly VaR

It is shown in the figures above that Shibor risk fluctuates around a level. The possibility of strengthening the risk is low. From 2007 to 2008, 2011 to 2012, 2013 to 2014, four products of Shibor all experienced great fluctuation. However, from 2015 to 2016, fluctuation all tends to remain moderate.

In order to ensure the effectiveness of the model, $\mathrm{VaR}$ values have to be tested. The simplest method is chi square test. The mean value calculated by VaR chi square test is compared to the critical value under corresponding degree of freedom. If the mean value is lower than the critical value, VaR is effective. The VaR chi square test of four products is displayed in Table 6.

Table 6 Chi Square Test

\begin{tabular}{lllll}
\hline & Overnight VaR & Weekly VaR & Biweekly VaR & Monthly Var \\
\hline CHI & 0.512526 & 0.303495 & 0.256586 & 0.229514 \\
\hline
\end{tabular}

When the degree of freedom equals 2 or 3 and $95 \%$ confidence level is selected, critical value is $5.991-7.815$. Four products of Shibor VaR are all less than the critical value, indicating that four VaR are all effective. Table 7 summarizes charateristics of four VaR.

Table 7 VaR Descriptive Statistics

\begin{tabular}{|l|l|l|l|l|}
\hline VaR & Overnight VaR & Weekly Var & Biweekly VaR & Monthly VaR \\
\hline Mean & 1.921314 & 2.670596 & 2.977851 & 3.385352 \\
\hline Maximum & 7.379888 & 7.773530 & 7.711069 & 8.061110 \\
\hline Minimum & -3.540226 & -0.848134 & -1.778313 & 1.000133 \\
\hline Std. Dev. & 0.810479 & 1.033159 & 1.149788 & 1.269154 \\
\hline
\end{tabular}

It is shown in Table 7 that overnight $\mathrm{VaR}$ has the lowest mean and volatility is similar with the one of GRCH model conditional volatility. The data of Shibor overnight VaR is the most accurate one to forecast the future 
trend of Shibor return. China's interest rate risk management must be modified to avoid great fluctuation or abnormal phenomenon.

\section{Policy Implication}

Based on empirical results above, this paper proposes policy implication of dealing with internal and external problems in interest rate risk management. First of all, it is imperative to improve relevant system of interest rate marketization process. Considering successful experience of western developed countries' marketization process, it is found that the completion of interest rate marketization process has great impact on the financial market and the whole real economy. Although China is in the transition stage, the challenges and risks faced by commercial banks will be larger in the accelerating interest rate marketization process. Financial supervision department should improve and prefect China's interest rate risk management system of commercial banks and modify corresponding policy and regulation. Besides, once the interest rate marketization process is completed, the role of central bank is turned from direct manager to indirect regulator. Hence, indirect regulation transmission mechanism should be prepared. Mixed operation of commercial banks in the future should be coordinated with corresponding policy and regulation in all related areas.

It is also recommended that China establish overall risk management system. Interest rate marketization brings commercial banks more autonomy. In addition, factors that influence interest rates will become more and more complex. Due to the fact that spot rate will be formed in the market, different factors will interact with each other. In the background of more and more complex environment, interest rate risk is not the only factor necessary to be considered in commercial banks, but credit risks and others should be taken into consideration. The serious consequence of 2008 financial crisis warns that overall risk management is necessary and crucial.

This paper recommends commercial banks to establish interest rate risk management database. With a higher subjective requirement of risk management, the development of interest rate risk management should be supported by quantized econometrics no matter in the aspect of measurement or forecast. The maturity of measurement method and technical methods require a higher standard of data from the aspect of accuracy and adequacy. The late start of China's commercial bank risk management causes a large gap compared to the interest rate market in western developed countries. For example, China's database of interest rate risk management in the commercial bank has not been established. In addition, the classical management system of China's commercial banks leads to untimely delivery and sharing and information opacity, which is harmful for commercial bank 
interest rate risk management and stable development of the financial market.

In recent years, method of financial measurement is developing rapidly, which creates a lot of models fitting commercial bank interest rate risk management. VaR model is one of them. Not only does it help quantify vague concept of risk, but it is appropriate for commercial bank's overall risk management. The usage of $\mathrm{VaR}$ model can significantly improve overall risk management level, especially in the mixed operation. VaR method can measure various factors influencing investment portfolio while high leverage ratio of financial derivatives enhances the interest risk. Hence, it is necessary to take VaR method to manage interest rate risk.

Last but not least, it is important to identify the function of risk management department in the commercial bank. In the long run, due to the particularity of Chinese regime, China's commercial bank interest rates are in the control of the central bank, causing a lower fluctuation and less attention. The risk management department in the commercial bank does not do their best to work well. Risk management department should accomplish risk control system instead of bearing the risk. The department should play a role in the measurement and prediction in the interest rate risk and offer a proposal to the management, so the management department can timely make adjustment to asset and liability.

\section{Conclusion}

This paper finds that China's interest rate market liberalization is in the preliminary stage. GARCH-VaR model is selected to measure the risk of Shibor. The data span from 2006 to 2016. VaR of four products of Shibor are calculated and compared. In general, the characteristics of "high peak and fat tail" of inter-bank offered rate can be found. It is fit well by GARCH model. Through calculation of $\mathrm{VaR}$ risk measurement it is found that $\mathrm{VaR}$ can fit Shibor risks well. In the four products of Shibor, overnight VaR has the lowest risk. Empirical results warn the financial supervisor and investors. It is critical to have an effective measurement of the interest rate risk through appropriate model. Besides, effective management is necessary to prevent accidents from happening.

\section{References:}

1. JPMorgan J. Autoregressive Conditional Heteroskedasticity with Estimates of the Variance of United Kingdom Inflation, Econometrica, 1982, (50):987-1008

2. Arvan, Brueckner J. Coherent Measure of Risk, Mathematical Finance, 1990, Vol.9 (3):203-228

3. Macaulay J. Techniques for Verifying the Accuracy of Risk 
Measurement Models, Journal of Derivatives, 1992, (12):73-84

4. G. Kaufman J, Nielson. Conditional Heteroskedasticity in Asset Returns: A New Approach, Econometrica, 1995, (59):347-370

5. Cox, Ross J. Duration and Measurement of Basis Risk, Journal of Business. 1999, (52):51-61

6. Philippe Jorion M. Value at Risk: The New Benchmark for Controlling Market Risk, New York: McGraw-Hill, 1997

7. Chew, Lilian M. Managing Derivative Risks, New York: John Wiley \& Sons, 1996

8. Berkowitz, J., Christoffersen, P., Pelletier, D J. Evaluating Value-atRisk Models with Desk-Level Data, Fourth Joint Central Bank Research Conference, 2008

9. Gabriela D R, Burkhard R J. Evaluating Density Forecasts with an Application to Stock Market Returns, Discussion Paper, Mar, Central Bank of Austria, 2002b: 192-222

10. Hull J, White A J. Incorporating Volatility Updating into the Historical Simulation Method for Value-at-Risk, Econometrica: Journal of the Econometric Society, 1982:987-1007

11. Vlaar P. J. G J. Value-at-Risk Models for Dutch Bond Portfolios, Journal of Banking and Finance, 2000, 24(7):1131-1154

12. Romano C R. Calibrating and Simulating Copula Functions: An Application to the Italian Stock Market, 2002:256-278

13. Armeana D J. Interest Rate Risk Management Using Duration GAP Methodology, The Cortical and Applied Economies, 2008(11):3-10

14. Embrechts P, Hoeing A, Juri A J. Using Copula to Bound the Valueat-Risk for Functions of Dependent Risks, Finance and Stochastics, 2003(7):145-167 